\title{
Alternative food chains as a way to embed mountain agriculture in the urban market: the case of Trentino
}

\author{
Emanuele Blasi, Clara Cicatiello*, Barbara Pancino and Silvio Franco
}

\author{
* Correspondence: \\ cicatiello@unitus.it \\ Department of Economics and \\ Management, Università degli Studi \\ della Tuscia, via del Paradiso 47, \\ Viterbo 01100, Italy
}

\begin{abstract}
Peri-urban agriculture is exposed to multiple pressures, which push to diversification and multifunctionality. However, the urban-rural link develops in different ways according to the features of the territories. A very interesting case is that of mountain areas, where the proportion among urban and rural domain is very skewed towards the latter and, at the same time, farms face major environmental problems that in most cases jeopardize their competitiveness in the mainstream market. Alternative food chains may play a key role in these contexts, especially for their ability to put farms in touch with the demand of consumers living in the urban areas located in the valley. In this paper we study the case of Trentino, an Italian Alpine region where alternative food chains are quickly developing, by comparing the development of alternative markets in this context with other Italian peri-urban areas. The mountain environment makes it very difficult for farms to standardize their products according to the requirement of the large retailers. Through alternative food chains, the typicality of products and the savoir faire of the farmers - representing the two main factors of products' added value - are endorsed and more easily communicated to the market. Data from a survey conducted on short food chain consumers show that they are inherently more careful to these particular cues of the products, as a result of a lifestyle that makes them more attached to identity and origins, as well as being more proud of their territory. These evidences confirm that in the Trentino area, for its structural and cultural traits, alternative food markets are meaningful for the survival and development of the local agricultural sector.
\end{abstract}

Keywords: Alterative food networks; Short food supply chains; Peri-urban agriculture; Rural-urban link; Mountain farming; Local products

\section{Background}

\section{Alternative food networks and urban proximity}

Recent research on the role of agriculture in urban and peri-urban contexts raises many questions about how the urban-rural link develops in regions and countries with different characteristics. Indeed, the problem of planning sustainable food production, distribution and consumption patterns should be related to the specificities of different territorial contexts. In this paper we investigate the emergence of local food chains in different contexts, focusing on the case of mountain areas, where these practices may play an important role in fostering the maintenance and the sustainability of agriculture.

(c) 2015 Blasi et al.; licensee Springer. This is an Open Access article distributed under the terms of the Creative Commons Attribution License (http://creativecommons.org/licenses/by/4.0), which permits unrestricted use, distribution, and reproduction in any medium, provided the original work is properly credited. 
The development of Alternative Food Networks (AFNs; Renting et al., 2003) is a central aspect of the urban-rural link, as they are very likely to develop in peri-urban contexts where the traditional agricultural functions are often replaced by non-agricultural or postproductive ones (Luttik and van der Ploeg, 2004). Defining AFNs is difficult, as the term has been used in different contexts and for different purposes. What most of the definitions share is an element of sense-making against the market and the rationale of agricultural industrialization (Holloway et al., 2006). It follows that AFNs are usually associated with all those local and ethical food chain systems which differ from mainstream food supply systems (Holloway and Kneafsey, 2004). Four main characteristics of AFNs are usually recognised: (1) a short distance between producers and consumers; (2) the involvement of small farms with a preference for ethical and responsible modes of production, in contrast with the industrial agribusiness approach; (3) the existence of food purchasing venues (both material and intangible) such as food cooperatives, farmers' markets, websites and so on; (4) a commitment to the social, economic and environmental dimensions of sustainable food consumption, distribution and production (Jarosz, 2008).

In the research on AFNs, many studies focus on how short food chain practices develop under different conditions. Short food supply chains (SFSCs) have been central to recent research on the emergence of alternative forms of agriculture and food supply in Western countries, as they are often understood as a consequence of the so-called turn to quality expressed by consumers in the food domain (Goodman, 2003). Indeed, in the mind of consumers they are associated with more traditional, locally embedded and sustainable farming practices (Ilbery and Maye, 2005), although this perception may sometimes be incorrect, as "local" is not in itself a guarantee of "a strong turn to quality based production" (Winter, 2003).

Rooted in the context of the emergence of many alternative forms of agriculture and food networks, SFSCs are characterized by the proximity of producers and consumers, either relational - i.e. with few (or even no) intermediaries between producers and consumers - or physical - i.e. a short geographical distance between them (Aubry and Kebir, 2013). Ideally, they fulfil both these conditions (Pascucci, 2010). These features are inherent to different types of SFSCs, ranging from direct sale at farm shops to farmers' markets, internet sale and organized box schemes. The considerable social involvement of the participants is another key feature of SFSC practices, due to both their embeddedness in the local community (Sage, 2003) and the social interactions that are likely to take place in these alternative markets (Cicatiello et al., 2014).

How does the urban-rural link contribute to the emergence of SFSC practices? The proximity to urban centres provides farmers with both an opportunity and an incentive to restructure their operations with a multifunctional approach. Namely, the development of alternative food chains is highly influenced by two main processes: urbanisation and rural restructuring, together with their mutual interaction (Jarosz, 2008). In past decades, diversification had been observed as a survival strategy in rural areas characterised by urban pressure (Ilbery, 1987; Bryant and Johnston, 1992), where consumer demand for agricultural goods and services appears to be much stronger than elsewhere.

First, agriculture is needed to help in the preservation of a quality environment and landscape. Indeed, agriculture plays a key role in managing the peri-urban landscape and the social, aesthetic and environmental functions of urban agglomerations nearby 
(Davoudi and Stead, 2007). Nonetheless, food production remains an important function of agricultural activities located in peri-urban areas. It has been observed that consumers increasingly prefer local produce because in local products they recognize added value related to tradition, quality and naturalness. As a result, consumers are increasingly willing to buy directly from producers, through alternative food chains at the local level (Pearson et al., 2011).

In response to these requests from urban consumers, more and more farms located in the surroundings of towns and cities are trying to meet this increasing demand, by offering recreational/leisure activities and making their products available to a greater share of urban consumers. In practice, this involves enhancing environmentally-friendly farming procedures, hobby farming, recreation-oriented diversification, social farming, short food supply chains and direct marketing (Zasada, 2011).

Of course, how farms respond to consumers' evolving demand is highly influenced by the territorial context where these processes take place. Namely, the geographical constraints of peri-urban areas, the features of the local agriculture (which may be more or less suited to multifunctional activities), the culture and traditions typical of each place, are all key factors to understanding the urban-rural link in different locations. In this paper we focus on the emergence of local food chains in a peri-urban mountain context, taking the Italian alpine region of Trentino as the focus of a case study. The particular interest of this case lies in the characteristics of mountain areas where, on the one hand, the traits of the pre-existing agricultural activities might encourage the development of multifunctional activities and, on the other hand, the link with the urban domain is perhaps weaker than elsewhere for geographical reasons. We argue that these factors are able to shape the development of local food chains by influencing consumer and producer approaches to alternative markets, so as to distinguish them from the rural/urban interactions that take place on the urban fringe of the cities. In order to explore these issues in the following sections we report the results of an empirical study performed in 2012 on 745 SFSC consumers, both in Trentino and in four peri-urban contexts. The exploratory study conducted to understand the development and features of local food chains allows us to identify the unique elements of SFSC development in Trentino through a comparison with SFSC practices in other Italian peri-urban areas. This comparison will highlight how studying the specificities of such a mountain context may improve understanding of how local specificities and constraints affect or enhance the development of short food chains, thus contributing to the ongoing research into these practices.

\section{Investigating SFSCs in Trentino Context}

Mountain areas represent a very interesting context for studying the development of alternative marketing networks. Indeed, in these areas the proportion of urban and rural domains is very skewed towards the latter and, at the same time, farms have to work in a hard environment, which in most cases jeopardizes their competitiveness in the mainstream market. This is the reason why alternative food chains may play a key role to the survival of agricultural operations in these contexts, especially thanks to their ability to put farms in touch with the demand of consumers living in the urban areas located in the valley, thus safeguarding their survival. 
In Trentino SFSCs are well developed, with about 10\% of farms selling their products directly to consumers, mostly by means of farmers' markets and direct sale at the farm as well as with more innovative means, such as solidarity purchase groups and community-supported agriculture (Marino et al., 2013). Many highly-innovative practices and experiments have been reported there. This is due to the particular features of the local agricultural sector which is made up almost exclusively of small and microfarms, often located in areas with poor accessibility and facing environmental, climatic, geographic and logistical challenges which affect their competitiveness on the market. These farms play a very important social and environmental role in representing the outpost of human influence in amidst the mountain wildlife, and their survival has so far mainly depended on widespread cooperation. This type of supply chain, while it guarantees the farmer - whether professional or part-time - a reliable and fairly profitable market, it certainly limits independence and decision-making power over which strategies to implement (Raffaelli et al., 2009).

This is perhaps the reason why some farms have started to experiment with new, more direct and autonomous ways of putting their products on the market, with the aim of maximising the value of their specificities. Alpine huts were the first farms to develop in this sense: each estate produces its own cheese, which is unique as its qualities are determined by a set of geographic variables (altitude, exposure of the slope), inputs (such as grazing) and technical skills (know-how of the farmer). The cheese is sold directly on site to tourists who come during the summer or in the villages, when the farmer goes back to the valley at the beginning of the autumn.

Practices such as these have spread more widely in recent years, and with the opening of the first farmers' markets, many other farms have entered SFSCs. Coldiretti, the major Italian farmers association, has acted as the main promoter of the diffusion of farmers' markets, in this region as well as in other parts of Italy. In 2006 it promoted the first farmers' market in Trentino, located in the central square of Trento, which was then followed by 10 other markets organized every week in the main urban centers of the region. In these markets locally-produced cured meats, cheeses and numerous heritage varieties of fruit and vegetables from the different valleys are sold, their value maximised through direct contact with consumers.

Beyond farmers' markets and direct sale on the farms, the region has also launched innovative forms of SFSCs. Solidarity purchase groups (henceforth referred to as GASs using the Italian acronym Gruppo di Acquisto Solidale) are widely spread in the area, where they have developed following a well-established trend in many Italian regions (Cembalo et al., 2013). As many as 16 of these practices may be counted in the city of Trento alone, while at least another 14 operate in different towns in the region. A GAS often emerges from informal associations based on the sharing of common values, such as ethical consumerism, attention to the environment, proximity among families, the desire to support local agriculture and so on (Migliore et al., 2012). Some early experiences of Community Supported Agriculture are also reported, such as the "Adopt a Cow" scheme, which involves consumers in the sustenance of cattle in winter, thus providing them with dairy products to be collected at the Alpine huts during the summer.

However, the different types of SFSC operating in the Trentino region seem much less urban-centric than in other areas studied. Indeed, the city of Trento, although it 
counts over 100,000 inhabitants and is surrounded by agricultural land, appears to be quite distant - in both geographical and relational - from the rural domain that in this region is primarily located in the mountains. This is primarily because the mountainous terrain in the region makes communication difficult, but also because there are so many small but very cohesive and distinct local communities.

\section{Methods}

A survey on the development of SFSCs was carried out in the Trentino region in 2012. It was part of a larger project funded by the Italian Ministry of Agriculture and carried out by CURSA (University Consortium for Socioeconomic and Environmental Research), with the aim of analysing the features and development of different types of SFSCs in a variety of territorial contexts. To do this, consumers participating in different forms of SFSCs were surveyed in 5 Italian areas (two metropolitan areas, two middle-size towns and one mountain area - Trentino). For the purpose of this paper, the data gathered through this survey made it possible to analyse the features of SFSCs in Trentino in comparison with the similar practices in other Italian peri-urban contexts, so as to highlight the specificities of the area.

Given the exploratory aim of the study, a mixed quantitative-qualitative research approach was applied to the survey, by administering a questionnaire directly to the consumers and conducting interviews with farmers. We used convenience sampling, which is well-suited to exploratory studies, as it provides a gross estimate of the result, although it remains a non-probabilistic sampling method (Guerrero et al., 2010).

The study included a total of 39 SFSC practices, among which:

- 16 farm shops (2 in Trentino);

- 11 farmers' markets (1 in Trentino);

- 9 GASs (2 in Trentino)

- 3 CSA practices (1 in Trentino - the above-mentioned Adopt a Cow scheme).

The questionnaire was made up of 9 closed questions, concerning:

- general consumer food shopping habits (food expenditure, habitual food stores etc.);

- consumer food shopping habits at SFSCs (expenditure, frequency of participation, products purchased etc.);

- consumer motivations for participating in SFSCs;

- information about consumer demographic profiles.

The questionnaire was administered to consumers shopping at farm shops, farmers' markets, GASs and CSA experiences. In the first two cases, consumers were interviewed face-to-face directly at the shops or the markets, after having completed their purchases. Instead, as GAS and CSA consumers usually keep in contact with the organizers through emails, in these cases the questionnaire was administered in an online version and sent to their email address. The data retrieved were all fed into an online structure so as to build a single database that was used as the basis for data processing. In total, 745 SFSC consumers (142 of which in Trentino) participated in the survey. 
For the purpose of this paper, we will analyse the results of the survey by comparing the results obtained in Trentino with those related to SFSCs in other areas, with the aim of highlighting the features that SFSC practices assume in the particular context of Trentino. The differences between Trentino and the other contexts were tested using ANOVA and Chi-square analyses so their statistical significance could be considered in the discussion.

We also performed in-depth interviews with 12 farmers involved in the SFSC practices analysed in the survey held in Trentino, in order to get producers' opinions about their operations and development. The interviews were carried out face-to-face, directly at the farms or, for the 4 farmers involved in the farmers' market, at the end of the market. The interviews were carried out as a conversation with the farmers, using the following outline:

- main features of the farm;

- marketing channels of the farm;

- motivations for joining SFSC practices;

- pros and cons of participation in SFSCs.

The qualitative information provided by the farmers during the interviews is explored in the discussion to enrich the analysis and more deeply understand the specific features of SFSC practices in Trentino.

\section{Results and discussion}

Out of 745 respondents to the questionnaire directed at SFSC consumers, 142 consumers were interviewed in Trentino. They are divided among the different chain types as shown in Table 1.

In about $60 \%$ of cases the respondent was a woman. Both in Trentino and in the other territorial contexts a higher quota of women was reported among the respondents interviewed at farmers' markets and farm shops than among GAS consumers. The average age of the consumers was about 50, which may explain the small size of the average household and the absence of children among the components of the households (on average less than 1 child per family). However, the respondents interviewed in Trentino were a little younger, although this difference was not very significant and their families were larger: $14 \%$ were made up of 5 or more components whilst in the peri-urban contexts analysed large families represented less than $7 \%$ of the sample.

Table 1 Respondents divided per SFSC type in the different contexts analysed

\begin{tabular}{|c|c|c|c|c|}
\hline \multirow[t]{2}{*}{ SFSC type } & \multicolumn{2}{|l|}{ Trentino } & \multicolumn{2}{|c|}{ Peri-urban contexts } \\
\hline & $\begin{array}{l}\text { Number of } \\
\text { respondents }\end{array}$ & $\begin{array}{l}\text { Quota of } \\
\text { respondents }\end{array}$ & $\begin{array}{l}\text { Number of } \\
\text { respondents }\end{array}$ & $\begin{array}{l}\text { Quota of } \\
\text { respondents }\end{array}$ \\
\hline $\begin{array}{l}\text { Farmers' } \\
\text { market }\end{array}$ & 31 & $22 \%$ & 258 & $43 \%$ \\
\hline Farm shop & 34 & $24 \%$ & 209 & $35 \%$ \\
\hline GAS & 71 & $50 \%$ & 115 & $19 \%$ \\
\hline CSA & 6 & $4 \%$ & 21 & $3 \%$ \\
\hline Total & 142 & $100 \%$ & 603 & $100 \%$ \\
\hline
\end{tabular}


Despite these findings, in the households interviewed in Trentino the weekly expenditure for food was lower than in the peri-urban areas covered by the survey ( $€ 98$ in Trentino vs. $€ 111$ elsewhere, $\mathrm{p}$-value $=0.013$ ).

We asked consumers to state how much they usually spend when they purchase at SFSCs; results show that the average expenditure is about €27. Consumers from Trentino spend a little more for every purchase withSFSCs than the other respondents ( $p$-value $=0.0004)$, although this finding is not consistent across the SFSC types: higher expenditures are recorded for the households participating in GASs, probably as a consequence of the concentration of purchases in the orders, which are typically completed only once a month. Instead, farmers' markets and farm shop customers typically make their purchases once a week.

Most of the consumers interviewed had been purchasing at SFSCs for a long time: nearly half of them had been purchasing at SFSCs for more than 2 years, while only $5 \%$ were interviewed during their first contact with these practices. This finding is even more pronounced in Trentino than elsewhere, and chi-square analysis $(\mathrm{p}$-value $=0.085)$ confirms that Trentino consumers are more likely to have been purchasing at SFSC for more than 2 years than the other respondents (Figure 1). These results support the idea that Trentino is a stronghold of SFSC practices, with a loyal consumer base. Indeed, it seems that the recent development of SFSCs in this area is rooted in a strong attraction to alternative markets by consumers, which likely already existed.

How do SFSC consumers find out about these alternative opportunities for food purchase? As many as $48 \%$ of consumers surveyed mentioned "word of mouth" as the main source of information about SFSCs. In the case of farmers' markets and farm shops, physical proximity also plays a role, since these experiences provide a permanent location which is easy for consumers to notice when they pass nearby. In Trentino only 9 consumers (out of 142) mentioned formal communication sources such as internet and advertisements, whilst $60 \%$ stated they got to know about SFSCs experiences through word of mouth. Compared to the consumers interviewed in peri-urban contexts, they seem to value informal communication even more, as is shown in Figure 2 and confirmed by a chi-square analysis ( $\mathrm{p}$-value $=0.013$ ).

Within the territorial context of Trentino, perhaps more than elsewhere, the communication strategies often used for marketing purposes are not suitable for SFSCs, whose

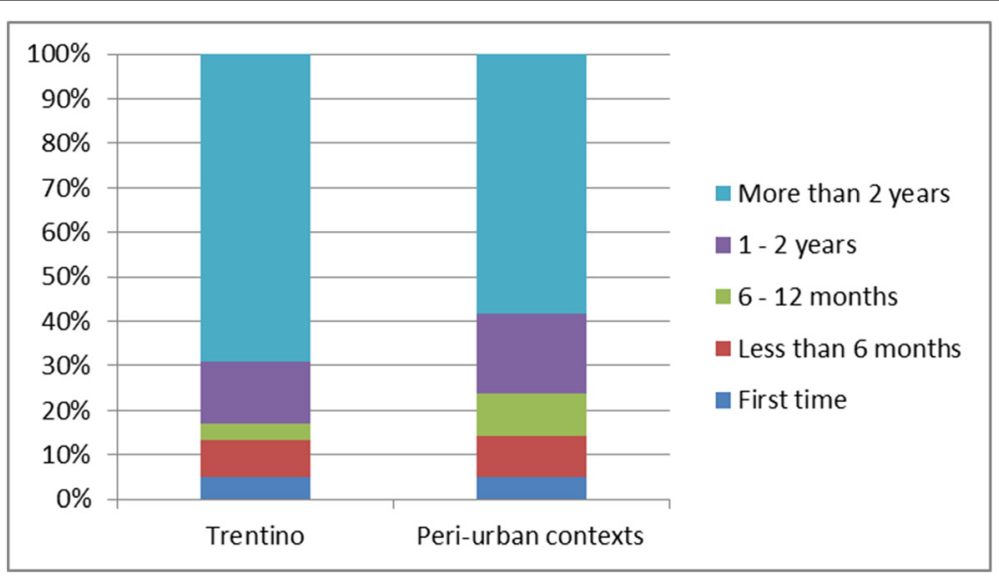

Figure 1 Results for the question "How long have you been purchasing with this SFSC?" 


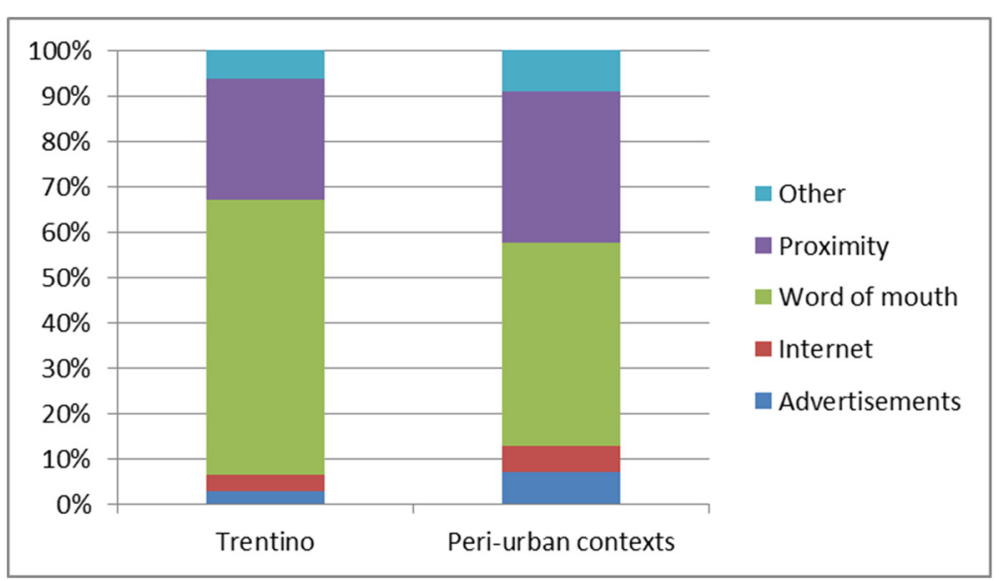

Figure 2 Results for the question "How did you find out about this SFSC?"

selling points can be communicated more effectively through direct contact between people rather than through the media. This is probably due to the very strong social network that still binds communities in the mountainous areas. The small size of villages, the sense of solidarity among people living in the mountains and the institutional effort to keep the local communities active result in a tendency to share ideas, opinions and events with neighbors and fellow citizens. This is likely to help spread information through informal channels much more than happens in peri-urban areas, thus making advertisement and other conventional communication strategies less effective and almost unnecessary. On the contrary, physical proximity assumes quite an import role in peri-urban contexts, where the wider adoption of SFSC practices in the urban network enhances the possibility for consumers to get acquainted with these practices in the course of their daily errands.

Interesting issues emerge from the analysis of consumer behavior at SFSCs. First, the products consumers buy with greatest frequency vary according to the type of SFSC. Almost all consumers buy fruit, vegetables and other fresh products at farm shops and farmers' markets, whereas GAS consumers are more likely to purchase processed non-perishable products, probably due to the longer time gap between deliveries. This is true in Trentino as well as in the other contexts analysed.

However, as we look at the marketing channels where consumers usually shop for food, some interesting differences emerge. In the questionnaire consumers were asked to indicate the quota of their total food purchases they usually buy through SFSCs and how the remaining quota is divided among other marketing channels. Their responses and statistical analyses confirm that in general consumers from Trentino have the tendency to concentrate their purchases at supermarkets, whereas urban consumers although they still prefer this marketing channel - display higher diversification in their choice of food outlets. Urban consumers probably have greater access to other types of food distributors such as grocery stores, discount retailers and large hypermarkets with respect to consumers living in mountainous areas, who for geographical reasons (distance to the nearest village/town, poor roads, snow in winter and so on) find it more difficult to travel. Therefore, when they do, they are likely to go to a single food store to stock up for a week or even longer. Beyond this somewhat expected finding, 
it's very interesting to look at the quota of their food consumers purchase at SFSCs. Here, a remarkable difference can be found across the SFSC types and between Trentino and peri-urban contexts, which clearly emerges by looking at the data presented in Figure 3, although this finding lacks statistical significance given the small sample size. GAS participants are much more devoted to SFSCs than other consumers, as they buy over 35\% of their food through GASs. This statistic is a little higher for Trentino, possibly because many consumers live outside the city in quite large houses, where they can stock large amounts of products. Farmers' markets and farm shops customers buy about $25 \%$ of their food at SFSCs, although for the farmers' market customers interviewed in Trentino this number is much lower than in peri-urban contexts. This may be due to the weekly opening of the farmers' markets operating in this area, whereas in the other contexts many farmers' markets open more often: twice a week or in larger cities such as Rome and Turin, even every day. Finally, as concerns CSA experiences, people participating in the Adopt a Cow project are much less devoted to alternative food provisioning channels, showing they are "newcomers" to SFSCs. On the contrary, the other CSA practices examined in the survey elsewhere provide participants with a higher quota of their food provisions.

Therefore, different forms of SFSCs have different capacities to act as major food provisioning channels for consumers: while a GAS is likely to become a dominant choice for food purchasing, other forms of SFSCs seem to be more suitable for complementing mainstream marketing channels. Namely, in Trentino more than elsewhere, the choice to participate in a GAS practice represents a crucial decision in the management of the food purchases for a household.

Finally, we analyzed the motivations that drive consumers to SFSCs. In general, the most important reasons refer to the distinctive elements of the products that can be purchased in these alternative chains: quality, healthfulness, local origin. GAS consumers mention ethical aspects such as environmental concerns and trust in the farmers more frequently, whereas farmers' markets and farm shops consumers have a weaker ethical set of motivations and mainly focus on the individual benefits that SFSC may deliver (e.g. quality and healthful products). At the other end of the ranking we surprisingly find motivations related to price and savings, which are scored much lower than the others. Although similar results have already emerged from

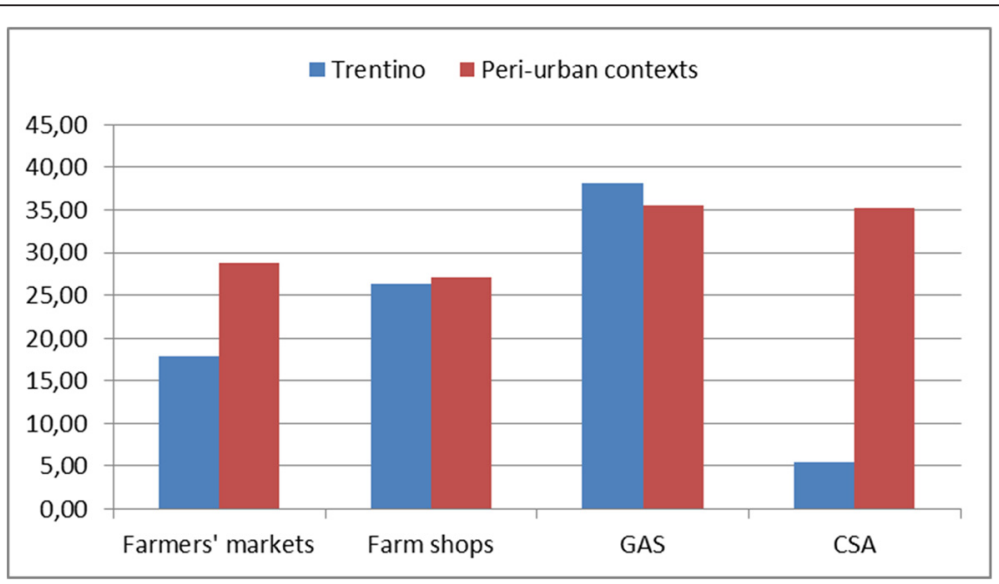

Figure 3 Food purchases at SFSCs in Trentino compared to peri-urban contexts. 
similar research done on Italian farmers' markets (Pascucci et al., 2011), these findings confirm that the search for the lowest price is not a key driver for consumers using all types of SFSCs.

However, some differences can be found among the different territorial contexts, as it is shown in Table 2. Namely, consumers from Trentino seem to be more concerned about their health and the environmental impact of their purchases than urban consumers; at the same time, although saving money is one of the less important motivations in general, consumers interviewed in Trentino do value this aspect a little more than the others. It seems that, on the one hand, their decision to participate in SFSCs is influenced by their belief that the products have a greater environmental value but, on the other hand, they still keep an eye on the economic aspect of the purchase. Instead, for urban consumers the convenience of alternative markets, i.e. their proximity, accessibility etc., is more important than for consumers living in a mountain context, although these differences are not statistically significant.

Greater insight into the specificities of SFSCs in Trentino emerges from the in-depth interviews we conducted with 12 producers participating in these experiences. Among them, 4 participated in a farmers' market, 3 belonged to a GAS, 3 sold their products at the farm and 2 were involved in the "Adopt a cow" scheme. Their farms were quite diverse both in size, ranging from very small (less than 1 hectare) to well over 50 hectares, and in location, with 5 farms located very high in the mountains, above 1,000 metres. This is maybe the reason why their points of view regarding SFSCs and the market in general is varied and diverse. Typical production at these farms included dairy products as well as fruit and vegetables, in line with the area's specialisation in livestock, apples and soft fruit.

Concerning their relationship with SFSCs practices, all the farmers said that SFSCs - very often more than one, as they tend to participate in several - is an important marketing channel, which absorbs a remarkable quota - often most of - their total production. However, some of them are still linked to the local farmers' cooperatives, which represent a low-risk option for selling their products. This tendency to specialize in SFSCs is the consequence of a general appreciation of these practices by the farmers, who state they are able to find, thanks to these networks, a marketing niche at the local level.

Among the reasons that support such a broad appreciation of the short chain, most of the farmers mention the desire to let consumers know more about the farm as well as a wish to have a direct relationship with them. This approach to SFSCs seems to go hand-in-hand with the trust consumers show towards the farmers, which may be the result of a positive exchange between them during purchases. The economic motivations, such as selling at a good price and retaining more value from the sale of quality products, are also quite important to farmers participating in farmers' markets or selling their

Table 2 Motivations of surveyed consumers for purchasing at SFSCs

\begin{tabular}{llllllll}
\hline Contexts & \multicolumn{7}{l}{ Motivations } \\
\cline { 2 - 7 } & $\begin{array}{l}\text { Healthful } \\
\text { products }\end{array}$ & $\begin{array}{l}\text { Quality } \\
\text { products }\end{array}$ & $\begin{array}{l}\text { Local } \\
\text { products }\end{array}$ & $\begin{array}{l}\text { Environmental } \\
\text { concerns }\end{array}$ & $\begin{array}{l}\text { Save } \\
\text { money }\end{array}$ & Convenience & $\begin{array}{l}\text { Trust in } \\
\text { producers }\end{array}$ \\
\hline Trentino & $4.85^{*}$ & 4.80 & 4.53 & $4.63^{*}$ & $3.50^{* *}$ & 3.23 & 4.36 \\
Peri-urban contexts & $4.75^{*}$ & 4.72 & 4.55 & $4.48^{*}$ & $3.23^{* *}$ & 3.41 & 4.40 \\
\hline
\end{tabular}

**The difference between Trentino and the other contexts is significant for $a<0.05$.

*The difference between Trentino and the other contexts is significant for $a<0.10$. 
products at a farm shop. Clearly, the price applied at these SFSCs - although not a significant driver to attract customers according to our survey, clearly satisfy the producers, at least when they value the earnings in comparison with mainstream marketing channels.

A primary motivation among farmers participating in GASs was their desire to be appreciated for the quality of their products, while the economic implications were much less important, although they said they were satisfied with the extra income they made through SFSCs. Hence, they have a very different approach to SFSCs, which matches that of GAS consumers.

The approach of farmers participating in the Adopt a Cow scheme was again different. They work under high environmental and logistic constraints, managing pastures located at considerable altitudes $(1500-1700 \mathrm{~m})$. Their participation in the project is therefore understood as a way to improve people's awareness of their traditional way of farming, thus improving tourism in the area, with significant economic implications, especially for those estates that have hospitality facilities available.

Therefore, it seems that producers' views of SFSCs match those of their consumers in several ways. In Trentino SFSC practices, perhaps more than elsewhere, the mutual influence of SFSC participants seems to shape the specific features of these practices in the particular context where they develop.

\section{Conclusions}

The conservation of agriculture in peri-urban environments is able to deliver environmental and recreational value to the city, as well as supporting the survival of local farms. In peri-urban contexts the role of traditional agricultural is likely to be replaced by non-agricultural or post-productive alternatives, thus pushing farms to move towards a multifunctional approach. These processes often support the development of AFN practices that complement rural/urban links.

In this paper we have analysed how such innovative food networks are shaped by the specific context of the Italian alpine region of Trentino.

Our analysis revealed that the Trentino area, due to its structural and cultural traits, is very well-suited for developing these practices, despite its geographical and logistical problems caused by its mountainous location. However, as a consequence of these specific traits, SFSCs have developed quite differently from in other Italian peri-urban contexts. Namely, by analysing the responses of SFSC producers and consumers in interviews and a survey in 2012, some interesting issues have emerged. For example, the consumers interviewed appear to be more loyal to SFSC practices than elsewhere, although they have emerged quite recently. Informal means of communication have proven to be very important to this purpose. At the same time, as expected, the geographical and logistical constraints typical of a mountain area seem to influence approaches to alternative markets, which are not likely to become a main source of food provision unless the SFSC scheme brings the products directly to consumers' homes, as is in the case of GASs. This is remarkably different from more urbanintegrated SFSC practices in which the SFSCs are more accessible and integrated into the everyday life of consumers, just like mainstream food stores.

By comparing the results of the survey administered to consumers with the opinions of farmers we talked to during in-depth interviews, it seems they share a similar approach to SFSC practices, probably as a consequence of the strong social capital they 
share, typical of mountain areas and small communities. This is maybe the reason why motivations related to quality and relations with other members of the community are key drivers for both to join SFSC practices.

In the end, SFSCs seem to be able, in the Trentino context, to reinforce the link between the mountains and the city. Indeed, it seems that consumer attitudes toward these practices are already very positive, thanks to their strong territorial identity. It follows that, rather than the farms responding to the needs of consumers as mostly happens elsewhere, in Trentino it is the consumers who satisfy the needs of the farms, for the sake of this bond. As we have seen, what farms need is mainly to protect their specific features and to communicate them to the market. Indeed, most of these farms could not be economically sustainable if they operated on the mainstream market, thus one of the few options they have is to take advantage of the uniqueness of their products, which are special both in terms of tangible (taste, traditional recipes, etc.) and intangible qualities (know-how of the farmer, relation to the local identity, etc.) to carve out a niche in the market. On the other hand, these consumers are inherently more aware of these needs, as a result of a lifestyle that makes them more attached to their identity and origins, as well as proud of their territory and the products that it can provide.

Therefore, there seems to be a natural match between the need of the farmers and the new demands by consumers. It follows that, despite the small size of the local market - only 3 of the 217 municipalities in Trentino have more than 20,000 residents - SFSCs have developed in a number of forms, thus contributing to the sustainability of the local agricultural sector. Of course, before considering the findings of this study for local policy planning, further research should be performed in order to confirm the characteristics observed. However, it seems that in the Trentino area SFSCs have the potential to play a key role in driving the development - or at least supporting - the agricultural sector in the area, and, at the same time, to foster social cohesion between rural and urban communities. From this perspective, it would be appropriate to support these practices in mountain communities, through rural development programs and local support of SFSC practices.

Of course, these findings need to be confirmed in further studies of other mountain communities. These might focus on the extent to which, in other international contexts, the same differences between mountain and peri-urban SFSCs may be found. Indeed, there is a gap in the research regarding how short food chain practices develop in particular environments such as the mountains. In-depth research in this domain may help to identify the opportunities that the development of SFSCs are likely to offer in these contexts. How can SFSCs contribute to supporting mountain agriculture and its sustainability? At the policy level, is it appropriate to support these farmsas a means to improve food system sustainability in mountain communities? Can the strengthening of local identity (e.g. through protected designations of origin) foster the development of SFSCs? These and other related questions provide the basis for an interesting stream of research to be undertaken in the coming years.

Abbreviations

AFN: Alternative food networks; GAS: Solidarity Purchase Group (from the Italian acronym Gruppo di Acquisto Solidale); SFSC: Short food supply chain. 
Authors' contributions

EB wrote the Results and discussion section. CC wrote the Background section. BP wrote the Method section. SF wrote Conclusions. All authors read and approved the final manuscript.

\section{Acknowledgements}

The authors wish to thank the University Consortium for Socioeconomic and Environmental Research (CURSA) and the coordinator of the project about short food supply chains in Italy, some data of which are here analysed. Our acknowledgements go to the researchers who worked on the project by carrying out the survey all over Italy. We also thank the anonymous reviewers whose comments were very useful to improve the structure and content of the paper.

Received: 15 July 2014 Accepted: 12 December 2014

\section{Published online: 29 January 2015}

\section{References}

Aubry C, Kebir L (2013) Shortening food supply chains: a means for maintaining agriculture close to urban areas? the case of the French metropolitan area of Paris. Food Policy 41:85-93

Bryant CR, Johnston TRR (1992) Agriculture in the City's Countryside. Belhaven Press, London

Cembalo L, Migliore G, Schifani G (2013) Sustainability and new models of consumption: the Solidarity Purchasing Groups in Sicily. J Agric Environ Ethics 26(1):281-303

Cicatiello C, Pancino B, Pascucci S, Franco S (2014) Relationship patterns in food purchase: observing social interactions in different shopping environments. J Agric Environ Ethics 27 (4). doi:10.1007/s10806-014-9516-9

Davoudi S, Stead D (2007) Urban-rural-relationships: an introduction and brief history. Build Environ 28:269-277

Goodman D (2003) The quality 'turn' and alternative food practices: reflections and agenda. J Rural Stud 19(1):1-7

Guerrero L, Claret A, Verbeke W, Enderli G, Zakowska-Biemans S, Vanhonacker F, Issanchou S, Sajdakowska M, Signe Granli B, Scalvedi L, Contel M, Hersleth M (2010) Perception of traditional food products in six European regions using free word association. Food Qual Preference 21(2):225-233

Holloway L, Cox R, Venn L, Kneafsey M, Dowler E, Tuomainen H (2006) Managing sustainable farmed landscape through 'alternative' food networks: a case study from Italy. Geogr J 172(3):219-229

Holloway L, Kneafsey M (2004) Producing-consuming food: closeness, connectedness and rurality. In: Holloway L, Kneafsey M (eds) Geographies of Rural Cultures and Societies. Ashgate, Aldershot, pp 262-282

Ilbery B (1987) The development of farm diversification in the UK: evidence from Birmingham's urban fringe. J Royal Agric Soc England 148:21-35

Ilbery B, Maye D (2005) Food supply chains and sustainability: evidence from specialist food producers in the Scottish/ English borders. Land Use Policy 22:331-344

Jarosz L (2008) The city in the country: growing alternative food networks in metropolitan areas. J Rural Stud 24(3):231-244

Luttik J, van der Ploeg B (2004) Functions of agriculture in urban society in the Netherlands. In: Brouwer F (ed) Sustaining Agriculture and the Rural Economy: Governance, Policy and Multifunctionality. Edward Elgar, Cheltenham, pp 204-222

Marino D, Cavallo A, Galli F, Cicatiello C, Borri I, Borsotto P, Di Gregorio D, Mastronardi L (2013) Esperienze di filiera corta in contesti urbani. Alcuni casi studio. Agriregionieuropa 32(9):1-7

Migliore G, Cembalo L, Caracciolo F, Schifani G (2012) Organic consumption and consumer participation in food community networks. New Medit (Suppl) 11(4):46-48

Pascucci S (2010) Governance structure, perception, and innovation in credence food transactions: the role of food community networks. Int J Food Syst Dyn 1(3):224-236

Pascucci S, Cicatiello C, Franco S, Pancino B, Marino D (2011) Back to the future? understanding change in food habits of farmers' market customers. Int Food Agribus Manag Rev 14(4):105-126

Pearson D, Henryks J, Trott A, Jones P, Parker G, Dumaresq D, Dyball R (2011) Local food: understanding consumer motivations in innovative retail formats. Br Food J 113(7):886-899

Raffaelli R, Coser L, Gios G (2009) Esperienze di filiera corta nell'agro-alimentare: un'indagine esplorativa in provincia di Trento. Econ Agro-alimentare 1:25-42

Renting H, Marsden TK, Banks J (2003) Understanding alternative food networks: exploring the role of short food supply chains in rural development. Environ Plan A 35(3):393-412

Sage C (2003) Social embeddedness and relations of regard: alternative 'good food' networks in south-west Ireland. J Rural Stud 19(1):47-60

Winter M (2003) Embeddedness, the new food economy and defensive localism. J Rural Stud 19(1):23-32

Zasada I (2011) Multifunctional peri-urban agriculture. a review of societal demands and the provision of goods and services by farming. Land Use Policy 28(4):639-648 